\title{
Green Approach for Synthesis of Cuo Nanoparticles and their Application in Antimicrobial Activity
}

\author{
Imran Hasan* and Parshotam Singh \\ Department of Chemistry, Environmental Research Laboratory, Chandigarh University, India
}

Submission: February 11, 2019; Published: March 19, 2019

*Corresponding author: Imran Hasan, Department of Chemistry, Environmental Research Laboratory, Chandigarh University, India

\begin{abstract}
With the rapid development of nanotechnology, much has been anticipated with copper oxide nanoparticles (CuO NP) due to their extensive industrial and commercial application. Copper oxide $(\mathrm{CuO})$ nanoparticles have attracted huge attention due to their catalytic, electrical, optical, photonic, textile, nanofluid, and antibacterial activity depending on the size, shape, and neighbouring medium. In the present paper, $\mathrm{CuO}$ nanoparticles are synthesized by using eco-friendly and non-toxic plants extract. The $\mathrm{CuO}$ nanoparticles are being synthesized by bottom up approach. $\mathrm{CuO}$ nanoparticles are used for various anti-bacterial treatments. Green plants extract is used for the efficient synthesis of $\mathrm{CuO}$ nanoparticles to obtain significantly active antibacterial material.
\end{abstract}

Keywords: $\mathrm{CuO}$ nanoparticles; Plants extract; Bottom up approach; Anti-bacterial activity

\section{Introduction}

The advances in nanotechnology have led to the great development in various fields including nanoparticles, nanotubes, and nanowire synthesis [1]. Copper oxide (CuO) nanoparticles has a wide range of applications in various fields, from energy conversion and storage through environmental science, electronics and sensors. $\mathrm{CuO}$ nanoparticles have received a lot of attention because they are the simplest members of the family of copper salts, and they possess a range of useful physical properties such as electron correlation effects, spin dynamics and high temperature superconductivity [2]. The increased demands with this utility have instigated a large production and use of these nanoparticles' day by day. This bulk production and usage have raised the concern over the toxicity of these nanomaterials on the ecosystem as well as on human health. Concerns over the toxic effect of $\mathrm{CuO}$ nanoparticles usage has drawn a specific attraction of toxicology researchers in last few years [3]. Copper oxide NPs are synthesised by numerous physical and chemical methods including sol-gel, microwave irradiations, sonochemical, electrochemical, alkoxide based route, thermal decomposition of precursor and liquid-liquid interface techniques involving organic solvents and harsh reducing agents [4]. However, these methods always involve utilization of hazardous organic solvents, toxic reagents, nonbiodegradable stabilizing agents and expensive instruments along with the tedious process control. Hence green synthesis is a better choice due to the eco-friendly approach of the synthesis [5]. Recently Many studies have been reported the cytotoxicity and genotoxicity of $\mathrm{CuO}$ nanoparticles through in vitro and in vivo investigation in mammalian cell line and animal models. The nanoparticles have also been used as nontoxic aqueous formulations for administration of cancer therapy [6]. Used $\mathrm{CuO}$ nanoparticles released in the aquatic environment also cause toxicity to fishes and aquatic animals. Copper and copper-based compounds are efficient biocidal properties [7], are now routinely used in pesticidal formulations [8]. Physical synthesis has been reported to have the issue of contamination however chemical synthesis is known for use of chemicals which could be harmful to the ecosystem as well as human health. Using biological agents like plants and microbes for synthesis process could be a potential solution to these problems. Recent advances in the field of science and technology, particularly nanotechnology, have led to the development a new concept of synthesizing nanosized particles of desired size and shape [9]. Of the available processes, biosynthesis of nanomaterials using green reducing agents and plants has been reported [10]. Biosynthesis process have a lot of advantages in the synthesis of nanoparticles due to cost-effective, eco-friendly and better alternative to physical and chemical methods [11]. Moreover, other chemical methods employ toxic chemicals, additives or capping agents and non-polar solvents in the synthesis procedure and are thus not suitable for their application in clinical and biomedical fields. The aim is to protect the environment and human health from toxic impacts of nanomaterials and their derived complex compounds and at the same time safely utilize nanomaterials. Environmental and biological risks for copper nanoparticles have been investigated by many researchers [12]. Data related to antimicrobial activity of $\mathrm{CuO}$ nanoparticles is very limited. Copper oxide is less expensive when compared 
to silver and gold which possess antimicrobial potential. $\mathrm{CuO}$ nanoparticles are potentially highly valuable antimicrobial agents since when synthesized, they possess extremely unusual crystal morphologies and high surface areas. In green synthesis of metal nanoparticles, the difficult task is to find a suitable and non-toxic natural product, as well as an eco-friendly solvent system. $\mathrm{CuO}$ is a p-type semiconductor material with a narrow band gap of $1.2 \mathrm{ev}$ Plants, algae, yeasts, fungi and bacteria can be applied as green approach for biosynthesis of metal NPs [13]. Hence, the present work has been undertaken to synthesize $\mathrm{CuO}$ NPs and to study their synergistic antimicrobial and activities [14].

\section{Discussion}

CuO NPs have been synthesized by various researchers from past few decades. One study reported the synthesis of $\mathrm{CuO}$ nanoparticles by reacting plant extract (fuel) with cupric nitrate as a source of copper in distilled water with constant stirring, after the formation of nanoparticles, they were placed in muffle furnace for calcination maintained at 400c [7]. Another study reported the synthesis of $\mathrm{CuO}$ nanoparticles by reacting plant extract with copper nitrate. Colour change of the reaction mixture was observed from deep blue to colourless and then to brick red and dark red on vigorous stirring for $24 \mathrm{hrs}$ at room temperature and the mixture is collected after discarding the supernatant. The collected CuO NPs can dry in a watch glass
[9]. Meanwhile another study reported the synthesis of $\mathrm{CuO}$ nanoparticles using combustion process by reacting leaf extract with copper nitrate trihydrate in double distilled water with constant stirring. The nanoparticles are produced by removing the ash content of plant extract [2]. Another study showed the synthesis of $\mathrm{CuO}$ nanoparticles by reacting plant extract with $\mathrm{CuCl}_{2} .2 \mathrm{H}_{2} \mathrm{O}$ and $\mathrm{NaOH}$ in presence of nitrogen. The colour of the mixtures gradually changed from bluish to black, indicating the formation of $\mathrm{CuO}$ nanoparticles [6]. Another study reported the synthesis of $\mathrm{CuO}$ nanoparticles by reacting plant extract with copper nitrate trihydrate. Deep blue colour of the copper nitrate solution changes to dark brownish colour. Dark brownish colour indicates the formation of $\mathrm{CuO}$ nanoparticles [11]. Another study reported the synthesis of $\mathrm{CuO}$ nanoparticles by reacting plant extract with $\mathrm{CuSO}_{4}$ solution. Colour change from brownish yellow to dark brown indicates the formation of $\mathrm{CuO}$ nanoparticles [10]. Another study reported the synthesis of $\mathrm{CuO}$ nanoparticles by reacting plant extract with copper sulfate under constant stirring. The black grinded powder is the $\mathrm{CuO}$ nanoparticles [8]. Another study reported the synthesis of $\mathrm{CuO}$ nanoparticles by reacting plant extract with copper nitrate trihydrate and the green coloured solution formed was boiled so that it turns into brown coloured paste. This paste was heated, and black coloured powder is formed. This black coloured powder are the copper nanoparticles [3,15] (Figure 1).

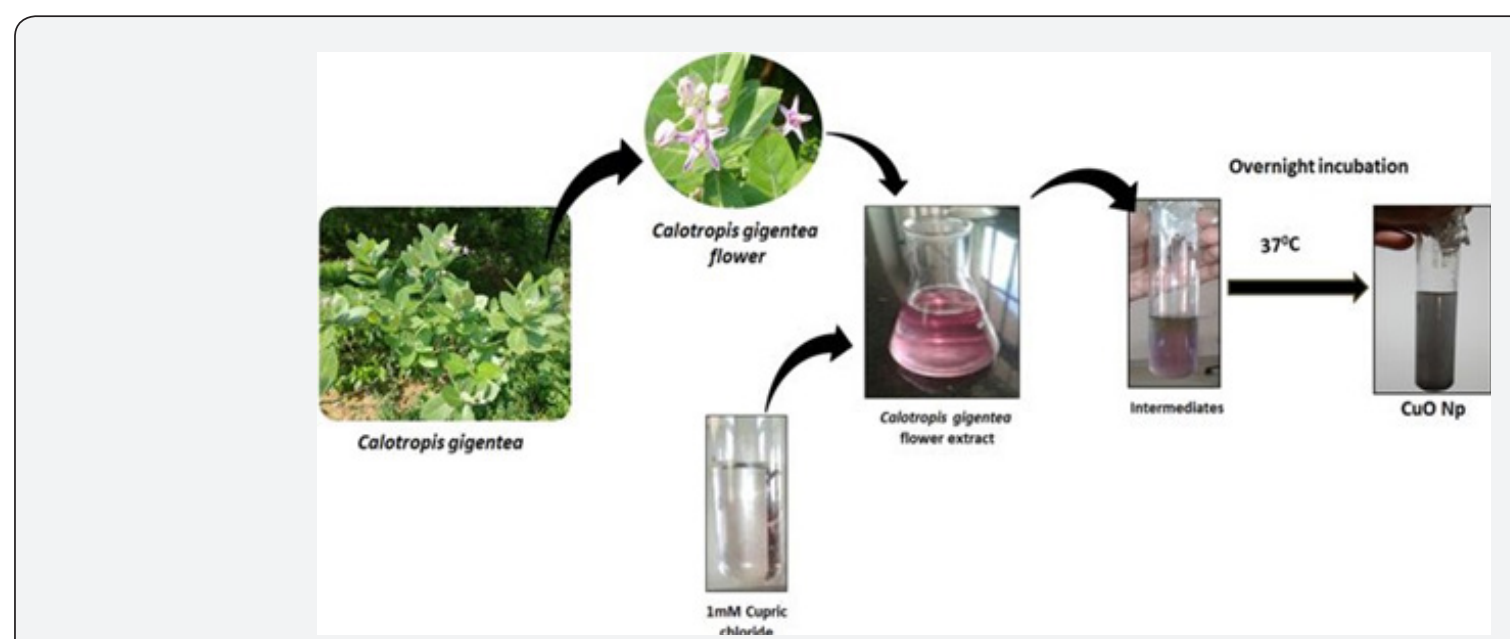

Figure 1: Schematic diagram of green synthesis of $\mathrm{CuO}$ nanoparticles from floral extract of Calotropis gigantea [15].

\section{Conclusion}

In conclusion, green synthesis of $\mathrm{CuO}$ nanoparticles is simple mild and environmentally friendly. $\mathrm{CuO}$ nanoparticles possess potent and desirable biological activities. These include good photo-catalytic, antimicrobial and antioxidant activities. In future, this green method of synthesizing $\mathrm{CuO}$ nanoparticles could also be extended to the fabrication of other industrially important metal oxides.

\section{Acknowledgement}

We gratefully acknowledged the Chandigarh University for providing me opportunity to write a review paper.

\section{References}

1. Hemalatha S, Makeswari M (2017) Green synthesis, characterization and antibacterial studies of $\mathrm{CuO}$ nanoparticles from Eichhornia Crassipes. Rasayan J Chem 10(3): 838-843.

2. Ijaz F, Shahid S, Khan SA, Ahmad W, Zaman S (2017) Green synthesis of copper oxide nanoparticles using Abutilon indicum leaf extract: Antimicrobial, antioxidant and photocatalytic dye degradation activities. Trop J of Pharm Research 16(4): 743-753.

3. Aminuzzaman M, Kei LM, Liang WH (2017) Green Synthesis of Copper Oxide (CuO) Nanoparticles using Banana Peel Extract and Their Photocatalytic Activities. Tech AIP Conf Poc 1828(1): 020016(1)-020016(5).

4. Hosseinzadeh R, Mohadjerani M, Mesgar S (2017) Green synthesis of copper oxide nanoparticles using aqueous extract of Convolvulus per- 
cicus L. as reusable catalysts in cross- coupling reactions and their antibacterial activity. IET Nanobiotechnol 11(6): 725-730.

5. Anantharaman A, George L, George M (2016) Green Synthesis of Copper Oxide Nanoparticles and Its Applications. Inter J of Advance Research in Sci and Eng 5(9).

6. Padil T, Cernik M, Vellora M (2013) Green synthesis of copper oxide nanoparticles using gum karaya as a biotemplate and their antibacterial application. Inter J of Nanomedicine 8(1): 889-898.

7. Naika H R, Lingaraju K, Manjunath K, Kumar D, Nagaraju D, et al. (2015) Green synthesis of $\mathrm{CuO}$ nanoparticles using Gloriosa superba L extract and their antibacterial activity J of Taibah University for Science 9(1): $7-12$.

8. Acharyulu NPS, Dubey RS, Swaminadham V (2014) Green Synthesis of $\mathrm{CuO}$ nanoparticles using Phyllanthus Amarus Leaf Extract And their Antibacterial activity Against Multidrug Resistance Bacteria. Inter J of Eng Research and Tech 3(4).

9. Kumar PPNV, Shameem U, Kollu P, Kalyani R L, Pammi S V N (2015) Green Synthesis of Copper Oxide Nanoparticles Using Aloe vera Leaf Extract and Its Antibacterial Activity Against Fish Bacterial Pathogens. 5(3):135-139

10. Shi LB, Tang PF, Zhang, Zhao YP, Zhang LC, et al. (2017) Green synthesis of $\mathrm{CuO}$ nanoparticles using Cassia Auriculata leaf extract and in vitro

This work is licensed under Creative Commons Attribution 4.0 License DOI: $10.19080 / I J E S N R .2019 .17 .555975$ evaluation of their biocompatibility with rheumatoid arthritis macrophages (RAW 264.7). Trop J of Pharmal Research 16(1): 185-192.

11. Narasaiah P, Mandal BK, Sarada NC (2017) Biosynthesis of Copper Oxide nanoparticles from Drypetes sepiaria Leaf extract and their catalytic activity to dye degradation. Materials Sci and Eng.

12. Saif S, Tahir A, Asim T, Chen Y (2016) Plant Mediated Green Synthesis of $\mathrm{CuO}$ Nanoparticles: Comparison of Toxicity of Engineered and Plant Mediated CuO Nanoparticles towards Daphnia magna Nanomaterials. 6(11): 205.

13. Taran M, Rad M, Alavi M (2017) Antibacterial Activity of Copper Oxide (CuO) Nanoparticles Biosynthesized by Bacillus sp. FU4: Optimization of Experiment Design. Pharmaceutical Sciences 23(3): 198-206.

14. Yugandhar P, Vasavi T, Devi PUM, Savithramma N (2017) Bioinspired green synthesis of copper oxide nanoparticles from Syzygium alternifolium (Wt.) Walp: characterization and evaluation of its synergistic antimicrobial and anticancer activity. Appl Nanosci 7(7): 417-427.

15. Kumari P, Panda PK, Jha E, Kumari K, Nisha K, Mallick MA, et al. (2017) Mechanistic insight to ROS and Apoptosis regulated cytotoxicity inferred by Green synthesized $\mathrm{CuO}$ nanoparticles from Calotropis gigantea to Embryonic Zebrafish. Nature Scientific Reports 7:1628416300.

\section{Your next submission with Juniper Publishers} will reach you the below assets

- Quality Editorial service

- Swift Peer Review

- Reprints availability

- E-prints Service

- Manuscript Podcast for convenient understanding

- Global attainment for your research

- Manuscript accessibility in different formats

( Pdf, E-pub, Full Text, Audio)

- Unceasing customer service

Track the below URL for one-step submission https://juniperpublishers.com/online-submission.php 